\title{
Quality of life, symptom severity and level of functioning in people with severe mental illness
} ready for hospital discharge

\author{
Chien \\ Wai Tong Chien ${ }^{1}$, David R. Thompson ${ }^{2,3}$, Sau Fong Leung ${ }^{4}$, Daniel Bressington ${ }^{5 *}$ \\ $\square$ \\ ${ }^{1}$ Nethersole School of Nursing, Chinese University of Hong Kong, Hong Kong SAR \\ ${ }^{2}$ School of Nursing and Midwifery, Queen's University Belfast, Belfast, UK \\ ${ }^{3}$ Department of Psychiatry, University of Melbourne, Melbourne, Australia \\ ${ }^{4}$ School of Nursing, The Hong Kong Polytechnic University, Hong Kong SAR \\ ${ }^{5}$ College of Nursing and Midwifery. Charles Darwin University, Australia \\ * Correspondence: \\ Prof. Daniel Bressington, College of Nursing and Midwifery, Charles Darwin University, \\ Casuarina, Darwin, Australia. daniel.bressington@cdu.edu.au \\ Conflicts of interest: \\ The authors declare that there is no conflict of interest.
}

Key words: severe mental illness; quality of life; symptom severity; functioning; cross-sectional study

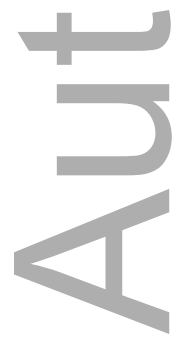

This is the author manuscript accepted for publication and has undergone full peer review but has not been through the copyediting, typesetting, pagination and proofreading process, which may lead to differences between this version and the Version of Record. Please cite this article as doi: 10.1111/JPM.12703

This article is protected by copyright. All rights reserved 
PROFESSOR WAI TONG CHIEN (Orcid ID : 0000-0001-5321-5791)

PROFESSOR DANIEL BRESSINGTON (Orcid ID : 0000-0003-0951-2208)

Article type :Original Article

-1.

(1)

Quality of life, symptom severity and level of functioning in people with severe mental illness ready for hospital discharge

\section{Relevance Statement:}

There is a lack of information on the levels of quality life and functioning of Asian people with severe mental illness immediately before hospital discharge, even though such information has major implications for psychiatric rehabilitation. The study findings highlight that mental health professionals should consider interventions beyond the traditional focus on psychopathology to improve functioning in people with SMI recently discharged from hospital. These should focus on improving social relationship functioning, supporting employment, and minimising the development and impact of physical illnesses. These interventions should be considered when preparing service users for hospital discharge and continued in the community setting.

\section{Abstract:}

\section{Introduction}

There is a lack of evidence on quality of life (QoL) and functioning in Asian people with severe mental illness (SMI) immediately prior to hospital discharge. This information could have major implications for treatment.

\section{Aim}


To profile perceived quality of life, symptom severity and level of functioning among people with SMI.

\section{Methods}

A cross-sectional study involving 347 adult inpatients with SMI. QoL (WHO Quality of Life - Brief Form), symptom severity (Positive and Negative Syndrome Scale) and level of functioning (Specific Level of Functioning) were measured immediately pre-discharge.

\section{Results}

Participants reported low social relationship-related QOL. Weak correlations were found between functioning, QoL and symptoms. Regression analysis identified the social relationship QoL domain, employment status, education level, living situation, physical illnesses, overall symptoms and the duration of receiving psychiatric services were statistically significant predictors of functioning levels.

\section{Discussion}

The findings may highlight a need for interventions beyond the traditional emphasis on psychiatric symptoms in order to improve functioning following an inpatient admission.

\section{Implications for practice}

Interventions to improve functioning in recently discharged people with SMI may need to be specifically designed to improve patients' social relationships, support return to employment and minimise the risk of physical illness.

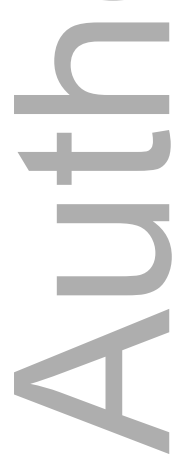

This article is protected by copyright. All rights reserved 


\section{$\longrightarrow$ \\ ( \\ Accessible Summary \\ What is known on the subject?}

- The quality of life (QoL) of people with severe mental illness (SMI) is a growing international concern.

- Many earlier studies report the determinants and correlates of QoL and functioning in people with SMI in Western countries.

- The QoL and functioning of Asian inpatients with SMI are largely unknown, particularly at the point where they have been assessed as being ready for hospital discharge.

\section{What the paper adds to existing knowledge?}

- Physical health, social functioning and community living skills, and negative symptoms are important areas of concern immediately pre-discharge.

- Social relationship related QoL, overall symptoms, unemployment, education level, living situation, physical illness and treatment duration predict functioning levels.

\section{What are the implications for practice?}

- Mental health nurses should consider interventions beyond the traditional focus on psychopathology to improve functioning outcomes in people with SMI recently discharged from hospital.

- Inpatient services should utilise the opportunity to monitor and address physical health problems before discharge from inpatient care.

Quality of life, symptom severity and level of functioning in people with severe mental illness ready for hospital discharge 


\section{Introduction}

Mental health problems are common and a leading cause of disability (Steel et al., 2014). Worldwide, an estimated 300 million people are affected by depression, about 60 million by bipolar affective disorder and about 23 million with schizophrenia, excluding those with other psychoses (WHO, 2018). Mortality is significantly higher among people with mental health disorders (particularly among those with severe mental illnesses) than the general population, accounting for 8 million deaths each year, and around 10 years of potential life lost per person (Walker et al., 2015). Thus, mental health problems impose substantial human, social and economic burdens on individuals, families, communities and societies as well as healthcare and social services. Unfortunately, many services are ill-equipped to respond adequately, with the result that there is poor quality of care for many of those who do receive treatment. Severe mental illnesses (SMI) include schizophrenia, bipolar disorder, schizoaffective disorder and major depressive disorder (Ritsner et al., 2012). In Hong Kong, with a population of over 7 million, extrapolation from worldwide data would indicate that between $70,000-200,000$ people have a SMI (Hong Kong Hospital Authority, 2011).

The quality of life (QoL) of people with mental disorders has been a growing international concern in mental health services. Health-related quality of life is affected in people with mental illness (Choo et al., 2017) and some studies also show that QoL is related to levels of subjective recovery (Temesgen et al., 2019). As patients with SMI have a particularly poor QoL

(Ritsner et al., 2012; Saharinen et al., 2011) and QoL measures are considered useful for care planning and evaluation (Trompenaars et al., 2006), healthcare providers should pay particular attention to enhancing the QoL of this population.

Correlations among QoL with symptom severity and level of functioning are well established (Kuehner and Huffziger, 2009; Trompenaars et al., 2006). For example, reducing symptoms (all types) is associated with higher QoL (van de Willige et al., 2005) and a systematic review conducted by Eack and Newhill (2007) suggested that psychotic symptoms in schizophrenia 
were significantly negatively related to all domains of QoL. Other studies have also shown that positive symptoms (such as hallucinations) are more strongly correlated with QoL than negative symptoms such as avolition and low creativity (van de Willige et al., 2005). Also, reduced QoL can be attributed to the side-effects of medication (Harvey et al., 2004) or symptoms of depression (Nørholm and Bech, 2006).

Although much research has been done regarding the determinants and correlates of QoL and functioning in people with schizophrenia and major depression in Western countries, little is known about this among all kinds of severe mental illness in Asian populations, including Hong Kong. A literature search revealed a dearth of studies with those available focused on community-dwelling people with SMI, after discharge from a psychiatric hospital and under community rehabilitation services (Cheung, 2001; Lee, 2008). Therefore, the QoL and functioning of inpatients with SMI starting from the point where they are considered ready for hospital discharge is largely unknown, even though such information can have major implications for their psychiatric rehabilitation post-discharge. This is also an important gap in understanding about this topic because considerable differences have been observed between Western and Asian countries on patient outcomes in SMI (Holla and Thirthalli, 2015); and conflicting findings of factors associated with QoL in SMI are reported in/between Asian and non-Asian settings (Choo, 2017). A clearer understanding of these issues would help mental health nurses, senior managers and policymakers focus both inpatient and community psychiatric services on the most important areas of QoL that require improvement immediately post-discharge and hence promote recovery and reduce disability.

Therefore, this study aimed to understand the factors affecting the functioning, QoL and mental health state of inpatients with SMI one week before hospital discharge. The objectives were to: (i) collect data to profile QoL, symptom severity, and level of functioning of a cohort of people with severe mental illness; and (ii) examine the relationships among demographic characteristics of people with severe mental illness, their QoL, symptom severity, and level of functioning.

This article is protected by copyright. All rights reserved 


\section{Methods}

A cross-sectional correlational study was conducted through face-to-face interviews to profile perceived QoL, symptom severity and level of functioning among hospital in-patients with SMI one week before their planned discharge.

\section{Sample}

A convenience sample of in-patients who met the following inclusion criteria was invited to participate in the study upon their planned discharge: (1) Hong Kong Chinese, (2) aged 18 to 65 years, (3) suffering from schizophrenia or other psychotic disorders using the consensus diagnosis according to the American Psychiatric Association DSM IV-TR, (4) one week before planned hospital discharge and (5) gave their voluntary consent. Patients were excluded from the study if they were: (1) suffering from a personality disorder, organic brain disease or learning disability, and (2) transferring to a general hospital for physical treatment.

The study was conducted in a large regional psychiatric hospital in Hong Kong providing comprehensive multidisciplinary inpatient services and community psychiatric care for a local population of around 1.2 million people. The 1,400-bed hospital consisted of 24 wards, in which approximately 970 patients with severe mental illness (SMI) were inpatients under treatment at subject recruitment.

\section{Sample size calculation}

A conservative minimum sample size required was determined based on the planned regression analysis. Considering that we would insert 17 demographic and clinical predictor variables into the multiple linear regression model, and using a widely accepted rule of thumb that 20 participants are required for each predictor variable (Stevens, 2009), we estimated that it required around 340 participants to ensure adequate study power of 0.80 . However, given 
the likelihood of a low response rate and improving the representativeness of the study, we recruited as many participants as possible over one year of data collection.

\section{Measures}

\section{Socio-demographic data}

Demographic data such as age, gender, employment status, educational level, type of residence and medical information (primary psychiatric diagnosis, duration of the illness, treatment and services received including nature and frequency) were recorded.

\section{World Health Organization Quality of Life - Brief Form (WHOQOL-BREF)}

QoL was measured using the WHOQOL-BREF (Chinese version) which is comprised of two general items and 26 items in four specific domains: physical (seven items), psychological (eight items), social relationship (three items) and environment (eight items). The transformed scores of the four domains range from 4 to 20. Two separate individual items with a global focus (overall quality of life and general health) are also calculated on a scale of 1-5. Higher scores indicate better QoL. The Chinese WHOQOL-BREF has shown good internal consistency, testretest reliability, and construct validity in studies in Hong Kong and Taiwan (Leung, 2005; Sung and Yeh, 2007).

\section{Positive and Negative Syndrome Scale (PANSS)}

Symptom severity was measured using the PANSS, an established rating scale in patients with schizophrenia (Kay et al. 1987). The scale has seven positive-symptom items and seven negative-symptom items. There are also 16 items designed to measure general psychopathology symptoms, which covers a broad evaluation of positive, negative and other symptoms like aggression, thought disturbance and depression. The measure uses a 7-point Likert scale. It has good to excellent inter-rater reliability, good internal consistency, good to fair test-retest reliability, and good concurrent and predictive validity (Bell, 1992) and has been used in studies of psychopharmacological treatment, cognitive functioning and course of illness (Kay et al. 1987). All research nurses who rated PANSS in this study were experienced in using 
the instrument and had previously received specific training on how to use the scale, however we did not formally establish inter-rater reliability as part of this study.

\section{Specific Level of Functioning (SLOF)}

Level of functioning was measured using the SLOF, a 43-item assessment scale grouped into six subscales: physical functioning; personal care skills; interpersonal relationships; social acceptability; activities of community living; and work skills (Schneider and Struening, 1983). Each of the questions in the above subscales is rated on a 5-point Likert scale $(1=$ poorest function, 5 = best function). The scale has been reported to have good psychometric properties in Chinese populations of people with SMI (Chien et al., 2006) and has been adopted by major psychiatric hospitals/units in Hong Kong since 2002. This scale is commonly used to evaluate psychosocial functioning in this patient group, reflecting their abilities to maintain their satisfactory performance of daily life and social activities in the community (Bowie et al., 2006). The scale is considered to be appropriate to assess health outcomes because lessening of symptoms and the reduction of relapse rates of SMI patients contributes to improve real-life functioning (San et al., 2007), which can reflect their cognitive and social competence (Bowie et al., 2006). Similarly to the PANSS, the nurse raters were trained how to use the SLOF and had extensive experience using the instrument in their clinical practice, but we did not test interrater reliability.

\section{Data collection and analysis}

Data were collected over one year between August 2011 and July 2012. Initially, potential participants who met the inclusion/exclusion criteria were identified by the trained research nurses after screening the patient lists and consulting with clinical staff. Subsequently, the research nurses (who had no role in the day-to-day provision of clinical care) facilitated the informed consent procedures and collected data from consenting patients via face to face interviews.

All data were coded and anonymized in the computerized data set. Missing data were imputed 
using group means. Descriptive statistics (mean, SD, range) were conducted to summarise the demographics, clinical characteristics and study outcome measures. Pearson correlations were conducted to examine relationships between patients' level of functioning with both symptoms and QOL.

We utilised multiple linear regression to address study objective II (examine the relationships among demographic characteristics of people with severe mental illness, their QoL, symptom severity, and level of functioning). After transforming all categorical variables into dummy variables and performing relevant screening procedures to ensure that assumptions were not violated (tolerance range 0.41 to 0.94 ; VIF range 1.06 to 4.43 ), linear regression analysis was performed to identify significant predictors of patients' functioning levels (SLOF total score). The recorded demographic/clinical characteristics, PANSS total score and the four WHOQOLBREF domains were inserted as predictor variables. Data were analysed using SPSS version 26. Statistical significance was set at $p<0.05$.

\section{Ethical considerations}

The study was approved by the relevant cluster research ethics committee of the Hong Kong Hospital Authority (NTWC/CREC/806/09) and the Human Subjects Research Ethics Committee of the University before recruitment. All participants were provided with written information about the study, given adequate time to consider their voluntary participation and informed that declining to take part would have no negative impact on their routine treatment. All participants provided written informed consent and were assured that they could withdraw from the study at any point without needing to provide a reason.

\section{Results}

A total of 600 patients who met the inclusion criteria were invited to participate in the study by the research nurses. Of these, 253 declined to take part. Finally, 347 (199 men, 148 women) inpatients aged from 18 to 64 (mean 41.6) years agreed to participate in the study and completed the measures (a response rate of 57.8\%). The majority of them were suffering from 
schizophrenia $(62.5 \%, \mathrm{n}=217)$ and the rest from major depression $(13.8 \%, \mathrm{n}=48)$, bipolar disorder $(13.3 \%, n=46)$, and psychotic disorders $(6.6 \%, n=23)$. The majority of participants were unemployed during the time of the interviews (73.5\%, $n=255)$. Most had received secondary school education or above $(81.0 \%, n=281)$. Their duration of hospitalization ranged from 2 to 180 days (mean 33.6) and duration of receiving mental health services ranged from 1 to 507 months (mean 131.1). Among them, 105 (30.3\%) patients had a co-morbid physical illness (Table 1).

In terms of QoL, patients reported a lower perceived QoL in the social relationship and psychological health domains than the physical health and environmental ones. In terms of symptoms (item mean scores), patients reported more severe general psychopathology symptoms than negative and positive ones (the three most severe general symptoms were anxiety, guilt feeling, and lack of judgment). In terms of aspects of functioning (standardised mean scores), patients reported that their skills in self-maintenance were better than their skills in social functioning and community living skills (Table 2 ).

Pearson correlation analyses (Table 3 ) indicated that the PANSS total score and all subscales had significant weak negative correlations with SLOF total score ( $r=0.22$ to 0.46 ); with negative symptoms having the strongest relationship. Similarly, all the QoL domain scores were significantly, but weakly correlated with SLOF total score $(r=0.14$ to 0.21$)$. However, the two individual items of QoL (overall health and overall QoL) were not significantly correlated to SLOF total score.

Regression analysis (Table 4) indicated seven statistically significant predictors of functioning levels. Living alone $(p=0.21)$, physical illness $(p=0.043)$, longer history of receiving psychiatric services $(p=0.002)$ and PANSS total score $(p<0.001)$ predicted worse functioning. Whereas, being employed ( $p=0.012$ ) and a higher level of education (secondary school or above) $(p=0.005)$ predicted a better level of functioning. The final regression model explained $36 \%$ of the variance in SLOF total score.

This article is protected by copyright. All rights reserved 


\section{Discussion}

To the best of our knowledge, this study is the first of its kind to be conducted in Hong Kong, and one of the few of a non-Western population to examine the relationship between QoL, symptom severity and level of functioning among in-patients with a severe mental illness who are about to be discharged from hospital.

Levels of functioning, symptoms and quality of life

The participants' levels of specific functioning in the current study were found to be generally suboptimal, but better than some other studies conducted with people diagnosed with SMI living in the community. For example, a multi-centre study involving 921 Italians with a psychotic illness reported mean subscale SLOF scores of $45.91(S D=8.5)$ for activities, $20.00(S D=$ 6.1) for work, and 22.31 ( $S D=6.0)$ for interpersonal relationships. Whereas the current study had subscale mean scores of 46.19 (SD=5.24), $22.57 \quad(S D=6.88)$ and 30.03 (SD=4.72) respectively. Similarly, the total mean SLOF score (173.24; SD=15.02) is far higher than the mean scores recorded at baseline in a Hong Kong study of a mindfulness-based intervention (Chien and Thompson, 2014) conducted with 105 people with schizophrenia (range 133.8 to 138.1; SD range 13.8-18.3). However, the two-year follow-up mean total SLOF score in the intervention group in Chien and Thompson's (2014) trial was reported as 176.9 (SD=22.1), which is very similar to the current study and thus may suggest that participants of the current study had responded relatively well to their inpatient treatment in terms of their functioning. Conversely, the levels of symptoms reported by participants in the current study were quite high (PANSS total score of 112.46; SD=23.41). This degree of psychopathology was found to correspond with a clinician rated severity of "severely ill" (using the Clinical Global Impressions Scale (CGI-S); Guy, 1976) within a secondary analysis of seven multicentre antipsychotic drug trials involving over 4,000 participants with schizophrenia (Leucht et al., 2005).

In terms of QoL, the social relationship domain score in this study was marginally lower 
compared with a previous study in Hong Kong of outpatients with schizophrenia (Xiang et al., 2007). Xiang and colleagues (2007) reported a mean social relationship QoL score of 12.76 $(S D=2.66)$, compared to the score of $10.70(S D=3.12)$ in the present study. A possible reason is that hospitalization limited the opportunity to enhance or maintain patients' social activities and social functioning. Support for this notion is provided by Hansson (2006), who found that patients in community care settings had a better subjective QoL than patients in hospital settings. Conversely, Adewuya \& Makanjuola (2009), who also used the WHOQOL-BREF to investigate the QoL of Nigerian schizophrenia outpatients, reported raw scores for overall QoL of 2.81 (SD =1.05) and a raw mean score for overall health of 2.94 (SD = 1.12). Whereas, the overall QoL score of 4.21 (SD=0.91) and the mean health score of $4.15(S D=1.06)$ in the current study are far higher than those reported by Adewuya \& Makanjuola. These large differences in QoL are a little surprising given that the Nigerian participants were living in the community and those in the current study were still hospitalised. This finding may be explained by the fact that Nigeria is an economically poor country in which access to adequate community-based healthcare is severely limited (Gureje et al., 2008) or perhaps because psychiatric care in Hong Kong is more advanced than Nigeria and although participants in the current study were inpatients, they were assessed as being ready for discharge to the community.

\section{Relationships between patients' functioning and symptom severity}

We found using bivariate correlations that there was only a weak relationship $(r=-0.23)$ between positive symptoms and functioning, whereas negative and general psychopathology symptoms had stronger correlations with the SLOF total score ( $r=0.47$ and 0.37 respectively). These results seem to be in accordance with an earlier Taiwanese study (Lin et al., 2013) that reported significant relationships between negative symptoms and functional outcomes, where negative symptoms were found to mediate the relationship between social cognition and neurocognition on functioning outcomes. Negative symptoms have also been reported to be associated with poor functional outcomes in people with schizophrenia after controlling for potential secondary sources of negative symptoms (i.e. anxiety, depression, antipsychotic side

This article is protected by copyright. All rights reserved 
effects) and cognitive deficits in a range of studies (Fervaha et al., 2014; Konstantakopoulos et al., 2011; Perlick et al., 2008; Rabinowitz et al., 2012), highlighting the central role these symptoms have in influencing functional outcomes. The importance of monitoring and relieving negative symptoms to improve patient outcomes, including to reduce the risk of rehospitalisation, was also recently illustrated in a retrospective study involving 450 people with schizophrenia spectrum disorders (Vita et al., 2019). This study investigated how the clinical profile of patients at the point of discharge from acute inpatient care was associated with the use of services over one-year follow-up, the findings revealed that number and duration of rehospitalisations were highest in those participants with more severe negative symptoms at discharge (Vita et al., 2019).

\section{Predictors of patients' functioning levels}

We found statistically significant but weak, bivariate correlations between different aspects of patients' QoL and symptoms with specific functioning levels. Regression analysis further identified that the social relationship domain of the WHOQOL-BREF, patients' employment status, education level, living situation, physical illnesses, overall symptoms and the duration of receiving psychiatric services were statistically significant predictors of specific functioning levels. Not surprisingly, employed patients may indicate better levels of social acceptability and more financial security (Choi et al., 2020; Na \& Lim, 2020). Similarly, without physical illnesses and a better QoL, it is to be expected that patients will have better levels of functioning (Malhotra et al., 2016). Also, to some degree, individuals with a higher education level may have better performance in their work and daily lives, and consistent with previous studies (Li et al., 2007; Mclntosh et al., 2011; Xiang et al., 2010), our results showed that education exerted a significant influence on functional capacity. Among the Chinese community, attaining a high level of education is much prized and this may the influence functional outcomes of people with SMI differently to other populations. Therefore, further research among Chinese populations of people with SMI should include consideration of their educational attainment. 


\section{Potential intervention targets}

Physical illness, social relationship related QoL, overall symptoms, living situation and employment status were potentially modifiable variables predicting patients' functioning levels, and therefore these factors may warrant greater attention as targets for intervention. Recent systematic reviews provide evidence that such targeted interventions have great potential to improve the physical health and employment status of people with schizophrenia (Vancampfort et al., 2019; Modini et al., 2016; Hjorth et al., 2014). For example, a meta-review of metaanalyses of randomized controlled trials to improve physical health state of patients with schizophrenia, including a total of over 47,000 participants (Vancampfort et al., 2019), demonstrated that non-pharmacological interventions such as lifestyle counselling and psychoeducation resulted in large effect sizes in weight reduction (SMD>0.9), however this review did not include employment related outcomes. Nonetheless, a systematic review and meta-analysis of individual placement and support vocational rehabilitation programmes (Modini et al., 2016) reported that they were effective interventions to facilitate a return to competitive employment in people with SMI across a variety of international settings with different economic conditions.

Our findings of the relationships between physical illness and reduced functioning may suggest that interventions targeting the encouragement of physical inactivity and reduction of sedentary behaviour are warranted to provide a comprehensive treatment package to enhance overall functional recovery. For example, people with SMI spend on average 8 hours per day being sedentary during waking hours and are significantly more sedentary than healthy controls: their mean amount of moderate or vigorous physical activity is about 38 minutes per day, being significantly lower than healthy controls (Vancampfort et al., 2017). However, people with severe mental illness face a range of barriers to engaging in physical activity and exercise, including high levels of perceived stress, low mood and a lack of self-confidence and poor social support (Firth et al., 2016). These barriers are often viewed as insurmountable by nurses who are involved in promoting the physical health of people with SMI (Hyland et al., 2003). In 
addition, a range of studies conducted in Asia (Bressington et al., 2018), the UK (Robson et al., 2013), Australia (Happell et al., 2013 ) and the USA (Knight et al., 2017) report that mental health nurses feel inadequately skilled to promote healthy lifestyles, highlighting a need to provide additional support and training for community-based mental health nurses for them to provide effective care.

As severe mental illness imposes a significant toll on individuals, families and communities and much of the burden is hidden, with premature deaths, unemployment, broken relationships, stigma and loss of self-esteem (Perry, 2014; Vigo et al., 2016; Brouwers, 2020), it is hardly surprising therefore that we found that this condition impacts adversely on QoL, symptoms and functioning. This indicates the need for careful individual assessment and interventions designed to address these aspects of functioning. The WHO's Mental Health Action Plan (20132020; WHO, 2013) recognizes the importance of the provision of comprehensive, integrated mental health and social care services in community-based settings, the implementation of strategies for promotion and prevention, and strengthened evidence and research base. In addition, a recent review of psychiatric rehabilitation services highlighted that the design and effective implementation of evidence-based recovery-focused services requires strong leadership and the establishment of quality legislation, effective coordinated action by stakeholders and the creation of culturally appropriate services (Hill et al., 2019). Thus, interventions should be specifically designed to reach this vulnerable population, tailored to address contextual factors, health concerns or health behaviours by gender, race or ethnicity and to take account of considerations such as cultural sensitivity. Also, low socioeconomic status, low health literacy and low awareness of health resources may result in impeded recognition of symptoms, fewer contacts with the healthcare system and low adherence to recommended lifestyle and medication. Thus, creative strategies need to be adopted by mental health nurses and other social and healthcare professionals to overcome these barriers so that interventions may be effective in improving quality of life, diminishing symptom severity and enhancing functioning.

This article is protected by copyright. All rights reserved 


\section{Implications for mental health nursing}

The findings of this study highlight that despite having low levels of positive symptoms and good self-maintenance skills, the social functioning and community living skills of participants were relatively poor. Also, having a lower level of social relationship related QoL was significantly related to lower levels of overall functioning in the regression model. These results, in conjunction with some previously published studies, seem to indicate that community-based Hong Kong mental health nurses should place more emphasis on promoting the social integration/functioning of people with SMI following discharge from inpatient services to build upon the levels of functional recovery achieved during acute inpatient care. Focusing on improving social relationships could also have positive impacts on indicators of clinical recovery, such as readmission rates, because numerous meta-analyses have reported that social skills training interventions result in significant moderate improvements in hospitalisation rates over a one to two-year follow-up period (Morin and Franck, 2017). The study findings that physical illness predicted a lower level of overall functioning may also highlight that inpatient services should utilise the duration of inpatient contact to effectively assess and address physical health problems before discharge from inpatient care. If physical illnesses are identified before discharge an ongoing management plan could be drawn-up and handed over to community services to ensure continuity of care and access to relevant physical healthcare services.

\section{Limitations}

This study has several limitations. This was a convenience sample limited to a local acute psychiatric hospital setting and therefore generalizability of the findings is limited. Similarly, participants in this study were about to be discharged and their health state is likely to be better than patients newly admitted. The response rate was only around $58 \%$, thus further replication studies are warranted to substantiate the veracity of our findings. It is also possible

that there was some variation in symptom measurement and assessment of functioning because although the nurse raters had received specific training and were experienced in using the instruments, a formal test of inter-rater reliability was not conducted. In addition, this study has a cross-sectional design and precludes examination of the causality between the 
independent and dependent variables. Finally, the strength of significant correlations was relatively weak and the regression model only explained $36 \%$ of the variance in total functioning scores, therefore other extraneous variables are likely to influence functioning and the clinical relevance of these findings should be interpreted with some caution. Despite these limitations, the study findings provide important information that can be used by Hong Kong mental health nurses and other professional groups to direct community-based interventions towards improving newly discharged patients' levels of social functioning, QoL and physical health.

\section{Conclusions}

Nurses, clinicians and policymakers should consider interventions beyond the traditional focus on psychopathology to improve functioning in people with SMI recently discharged from hospital. These should focus on improving social relationship functioning, supporting employment, and minimising the impact and development of physical illnesses. The regression model also revealed that the presence of physical illnesses, duration of receiving psychiatric services, being employed, living situation, overall level of psychopathology and education level appear to have a significant relationship with functioning levels. Thus, further research exploring the association of demographic data and clinical factors with level of functioning among this population is recommended.

\section{Acknowledgements}

We thank the patients who participated in this study and the research assistants and staff for their support and help.

\section{Funding}

The study was supported by the Commissioned Research on Mental Health Policy and Services, Food and Health Bureau, Hong Kong SAR Government (SMH-35).

\section{References}

This article is protected by copyright. All rights reserved 
Adewuya, A. O., \& Makanjuola, R. O. A. (2009). Subjective quality of life of Nigerian schizophrenia patients: sociodemographic and clinical correlates. Acta Psychiatrica Scandinavica, 120(2), 160-164. Doi: 10.1111/j.1600-0447.2009.01395.x

Bell, M., Milstein, R., Beam-Goulet, J., Lysaker, P., \& Cicchetti, D. (1992). The Positive and Negative Syndrome Scale and the Brief Psychiatric Rating Scale. Reliability, comparability and predictive validity. Journal of Nervous and Mental Disease, 180(11), 723-728. Doi:

10.1097/00005053-199211000-00007

Bowie, C. R., Reichenberg, A., Patterson, T. L., Heaton, R. K., \& Harvey, P. D. (2006). Determinants of real-world functional performance in schizophrenia subjects: correlations with cognition, functional capacity, and symptoms. American Journal of Psychiatry, 163(3), 418-425. Doi: 10.1176/appi.ajp.163.3.418

Bressington, D., Badnapurkar, A., Inoue, S., Ma, H. Y., Chien, W. T., Nelson, D., \& Gray, R. (2018). Physical health care for people with severe mental illness: The attitudes, practices, and training needs of nurses in three Asian countries. International journal of environmental research and public health, 15(2), 343. Doi: 10.3390/ijerph15020343

Brouwers, E.P. (2020). Social stigma is an underestimated contributing factor to unemployment in people with mental illness or mental health issues: position paper and future directions. $B M C$ psychology, 8, 1-7. Doi: 10.1186/s40359-020-00399-0

Cheung, H. K. (2001). A 2-year prospective study of patients from Castle Peak Hospital discharged to the first long-stay care home in Hong Kong. Hong Kong Journal of Psychiatry, 11(2), 1-12

https://link.gale.com/apps/doc/A169678961/AONE?u=hkpolyu\&sid=AONE\&xid=7d3abf62. Accessed 25/08/2020.

Chien, W. T., Chan, S. W., \& Thompson, D. R. (2006). Effects of a mutual support group for 
families of Chinese people with schizophrenia: 18-month follow-up. British Journal of Psychiatry, 189(1), 41-49. Doi: 10.1192/bjp.bp.105.008375

Chien, W. T., \& Thompson, D. R. (2014). Effects of a mindfulness-based psychoeducation programme for Chinese patients with schizophrenia: 2-year follow-up. The British Journal of Psychiatry, 205(1), 52-59. Doi: 10.1192/bjp.bp.113.134635

Choi, D. J., Joung, J., Kim, E., \& Kim, S. (2020). "Entry to the Society from the Schizophrenic Cave"-A Qualitative Meta-Synthesis of Job Experiences for People with Schizophrenia. Issues in Mental Health Nursing, 1-14. Doi: 10.1080/01612840.2020.1731892

Choo, C. C., Chew, P. K., Ho, C. S., \& Ho, R. C. (2017). Prediction of quality of life in Asian patients with schizophrenia: A cross-sectional pilot study. Frontiers in Psychiatry, 8, 198. Doi: 10.3389/fpsyt.2017.00198

Eack, S, \& Newhill, C. (2007). Psychiatric Symptoms and Quality of Life in Schizophrenia: A Meta-Analysis. Schizophrenia Bulletin, 33, 5, 1225-1237. Doi: 10.1093/schbul/sbl071

Fervaha, G., Foussias, G., Agid, O., \& Remington, G. (2014). Impact of primary negative symptoms on functional outcomes in schizophrenia. European Psychiatry, 29(7), 449-455. Doi: 10.1016/j.eurpsy.2014.01.007

Firth, J., Rosenbaum, S., Stubbs, B., Gorczynski, P., Yung, A. R., \& Vancampfort, D. (2016). Motivating factors and barriers towards exercise in severe mental illness: a systematic review and meta-analysis. Psychological medicine, 46(14), 2869-2881. Doi: $10.1017 / 50033291716001732$

Galuppi, A., Turola, M. C., Nanni, M. G., Mazzoni, P., \& Grassi, L. (2010). Schizophrenia and quality of life: how important are symptoms and functioning?. International journal of mental 
health systems, 4(1), 31. Doi: 10.1186/1752-4458-4-31

Gureje, O., Kola, L., Afolabi, E., \& Olley, B. O. (2008). Determinants of quality of life of elderly Nigerians: results from the Ibadan study of ageing. African journal of medicine and medical sciences, 37(3), 239. https://www.ncbi.nlm.nih.gov/pmc/articles/PMC2820711/. Accessed $25 / 08 / 2020$

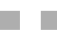

Guy, W. (1976). ECDEU assessment manual for psychopharmacology. US Department of Health, Education, and Welfare, Public Health Service, Alcohol, Drug Abuse, and Mental Health Administration, National Institute of Mental Health, Psychopharmacology Research Branch, Division of Extramural Research Programs.

Hansson, L. (2006). Determinants of quality of life in people with severe mental illness. Acta Psychiatrica Scandinavica, 113 (Suppl.), 46-50. Doi: 10.1111/j.1600-0447.2005.00717.x

Happell, B., Platania-Phung, C \& Scott, D. (2013). Physical health care for people with mental illness: Training needs for nurses. Nurse Education Today, 33, 396-401. doi:10.1016/j.nedt.2013.01.015

Harvey, P. D., Green, M. F., Keefe, R. S., \& Velligan, D. I. (2004). Cognitive functioning in schizophrenia: a consensus statement on its role in the definition and evaluation of effective treatments for the illness. Journal of Clinical Psychiatry, 65(3), 361-372. Doi:

\subsection{8/JCP.v65n0312}

Hill, H., Killaspy, H., Ramachandran, P., Ng, R. M. K., Bulman, N., \& Harvey, C. (2019). A structured review of psychiatric rehabilitation for individuals living with severe mental illness within three regions of the Asia-Pacific: Implications for practice and policy. Asia- Pacific Psychiatry, 11(2), e12349. Doi: 10.1111/appy.12349 
Hjorth, P., Davidsen, A. S., Kilian, R., \& Skrubbeltrang, C. (2014). A systematic review of controlled interventions to reduce overweight and obesity in people with schizophrenia. Acta Psychiatrica Scandinavica, 130(4), 279-289. Doi: 10.1111/acps.12245

Holla, B., \& Thirthalli, J. (2015). Course and outcome of schizophrenia in Asian countries: review of research in the past three decades. Asian Journal of Psychiatry, 14, 3-12. Doi:

10.1016/j.ajp.2015.01.001

Hospital Authority Mental Health Service Plan for Adults 2010-2015 [Internet]. Hong Kong: Hong Kong Hospital Authority; 2011. Available from:

http://www.ha.org.hk/ho/corpcomm/Strategic\%20Service\%20Framework/Mental\%20health\%2 Oservice\%20plan\%20for\%20adults2010-15.pdf. Accessed 25/08/2020

Hyland, B., Judd, F., Davidson, S., Jolley, D., \& Hocking, B. (2003). Case managers' attitudes to the physical health of their patients. Australian \& New Zealand Journal of Psychiatry, 37(6), 710-714. Doi: 10.1080/j.1440-1614.2003.01264.x

Jaracz, K., Kalfoss, M., Górna, K., \& Bączyk, G. (2006). Quality of life in Polish respondents: psychometric properties of the Polish WHOQOL-Bref. Scandinavian Journal of Caring Sciences, 20(3), 251-260. Doi: 10.1111/j.1471-6712.2006.00401.x

Kay, S. R., Fiszbein, A., \& Opler, L. A. (1987). The Positive and Negative Syndrome Scale (PANSS) for schizophrenia. Schizophrenia Bulletin, 13(2), 261-276. Doi: 10.1093/schbul/13.2.261

Knight, M.; Bolton, P.; Kopeski, L. (2017). Providing Physical Care to Persons With Serious Mental Illness: Attitudes, Confidence, Barriers and Psychological Empowerment. Archives of Psychiatric Nursing., 31, 447-453. Doi: 10.1016/j.apnu.2017.07.001

This article is protected by copyright. All rights reserved 
Konstantakopoulos, G., Ploumpidis, D., Oulis, P., Patrikelis, P., Soumani, A., Papadimitriou, G. N., \& Politis, A. M. (2011). Apathy, cognitive deficits and functional impairment in schizophrenia. Schizophrenia research, 133(1-3), 193-198. Doi: 10.1016/j.schres.2011.07.003

Kuehner, C., \& Huffziger, S. (2009). Subjective quality of life aspects predict depressive symptoms over time: results from a three-wave longitudinal study. Acta Psychiatrica Scandinavica, 120(6), 496-499. Doi: 10.1111/j.1600-0447.2009.01436.x

Leucht, S., Kane, J. M., Kissling, W., Hamann, J., Etschel, E., \& Engel, R. R. (2005). What does the PANSS mean?. Schizophrenia research, 79(2-3), 231-238. Doi: 10.1016/j.schres.2005.04.008

Leung, K. F., Wong, W. W., Tay, M. S., Chu, M. M., \& Ng, S. S. (2005). Development and validation of the interview version of the Hong Kong Chinese WHOQOL-BREF. Quality of Life Research, 14(5), 1413-1419. Doi: 10.1007/s11136-004-4772-1

Li, J., Lambert, C. E., \& Lambert, V. A. (2007). Predictors of family caregivers' burden and quality of life when providing care for a family member with schizophrenia in the People's Republic of China. Nursing \& Health Sciences, 9(3), 192-198. Doi: 10.1111/j.1442-2018.2007.00327.x

Lin, C. H., Huang, C. L., Chang, Y. C., Chen, P. W., Lin, C. Y., Tsai, G. E., \& Lane, H. Y. (2013). Clinical symptoms, mainly negative symptoms, mediate the influence of neurocognition and social cognition on functional outcome of schizophrenia. Schizophrenia research, 146(1-3), 231-237. Doi: 10.1016/j.schres.2013.02.009

Malhotra, N., Kulhara, P., Chakrabarti, S., \& Grover, S. (2016). Lifestyle related factors \& impact of metabolic syndrome on quality of life, level of functioning \& self-esteem in patients with bipolar disorder \& schizophrenia. The Indian journal of medical research, 143(4), 434. Doi: 10.4103/0971-5916.184284

This article is protected by copyright. All rights reserved 
McIntosh, B. J., Zhang, X. Y., Kosten, T., Tan, S. P., Xiu, M. H., Rakofsky, J., \& Harvey, P. D. (2011). Performance-based assessment of functional skills in severe mental illness: Results of a largescale study in China. Journal of Psychiatric Research, 45(8), 1089-1094. Doi:

10.1016/j.jpsychires.2011.01.012

Modini, M., Tan, L., Brinchmann, B., Wang, M. J., Killackey, E., Glozier, N., et al. (2016).

Supported employment for people with severe mental illness: systematic review and metaanalysis of the international evidence. British Journal of Psychiatry, 209(1), 14-24. Doi: 10.1192/bjp.bp.115.165092

Morin, L., \& Franck, N. (2017). Rehabilitation interventions to promote recovery from schizophrenia: a systematic review. Frontiers in psychiatry, 8, 100. Doi:

$10.3389 /$ fpsyt. 2017.00100

Na, E. Y., \& Lim, Y. J. (2020). Influence of Employment on the Positive Mental Health of Individuals with Schizophrenia Living in the Community. Psychiatric Quarterly, 91(1), 203-208. Doi: $10.1007 /$ s11126-019-09686-5

Nørholm, V., \& Bech, P. (2006). Quality of life in schizophrenia patients: association with depressive symptoms. Nordic Journal of Psychiatry, 60(1), 32-27. Doi:

$10.1080 / 08039480500504966$

Oliveira, S. E., Carvalho, H., \& Esteves, F. (2016). Toward an understanding of the quality of life construct: Validity and reliability of the WHOQOL-Bref in a psychiatric sample. Psychiatry research, 244, 37-44. Doi: 10.1016/j.psychres.2016.07.007

Perlick, D. A., Rosenheck, R. A., Kaczynski, R., Bingham, S., \& Collins, J. (2008). Association of symptomatology and cognitive deficits to functional capacity in schizophrenia. Schizophrenia research, 99(1-3), 192-199. Doi: 10.1016/j.schres.2007.08.009

This article is protected by copyright. All rights reserved 
Perry, B. L. (2014). Symptoms, stigma, or secondary social disruption: Three mechanisms of network dynamics in severe mental illness. Journal of Social and Personal Relationships, 31(1), 32-53. Doi: 10.1177/0265407513484632

Rabinowitz, J., Levine, S. Z., Garibaldi, G., Bugarski-Kirola, D., Berardo, C. G., \& Kapur, S. (2012). Negative symptoms have greater impact on functioning than positive symptoms in schizophrenia: analysis of CATIE data. Schizophrenia research, 137(1-3), 147-150. Doi: 10.1016/j.schres.2012.01.015

Ritsner, M. S., Arbitman, M., Lisker, A., \& Ponizovsky, A. M. (2012). Ten-year quality of life outcomes among patients with schizophrenia and schizoaffective disorder II. predictive value of psychosocial factors. Quality of Life Research, 21(6), 1075-1084. Doi: 10.1007/s11136-011-00154

Robson, D.; Haddad, M.; Gray, R.; Gournay, K. (2013). Mental health nursing and physical health care: A cross sectional study of nurses' attitudes, practice, and perceived training needs for the physical health care of people with severe mental illness. International Journal of Mental Health Nursing, 22, 409-417. Doi: 10.1111/j.1447-0349.2012.00883.x

Saharinen, T., Hintikka, J., Kylmä J., Koivumaa-Honkanen, H., Honkalampi, K., Lehto, S. M., et al. (2011). Population-based comparison of health-related quality of life between healthy subjects and those with specific psychiatric or somatic diseases. Perspectives in Psychiatric Care, 7(2), 66-73. Doi: 10.1111/j.1744-6163.2010.00273.x

San L, Ciudad A, Alvarez E et al. (2007). Symptomatic remission and social/vocational functioning in outpatients with schizophrenia: prevalence and associations in a cross-sectional study. European Psychiatry, 22:490-8. Doi: 10.1016/j.eurpsy.2007.06.005

Schneider, L. C., \& Struening, E. (1983). L. SLOF: A behavioural rating scale for assessing the 
mentally ill. Social Work Research \& Abstracts, 19(3), 9-21. Doi: 10.1093/swra/19.3.9

Skevington, S. M., Lotfy, M., \& O'Connell, K. A. (2004). The World Health Organization's WHOQOL-BREF quality of life assessment: psychometric properties and results of the international field trial. A report from the WHOQOL group. Quality of life Research, 13(2), 299310. Doi: 10.1023/B:QURE.0000018486.91360.00

Stevens, J. (2009). Applied multivariate statistics for the social sciences. New York, NY: Routledge, $5^{\text {th }}$ ed.

Sung, S. C., \& Yeh, M. Y. (2007). Factors related to quality of life in depressive outpatients in Taiwan. Psychiatry and Clinical Neuroscience, 61(6), 610-615. Doi: 10.1111/j.14401819.2007.01726.x

Steel, Z., Marnane, C., Iranpour, C., Chey, T., Jackson, J. W., Patel, V., et al. (2014). The global prevalence of common mental disorders: a systematic review and meta-analysis 1980-2013. International Journal of Epidemiology, 43(2): 476-493. Doi: 10.1093/ije/dyu038

Temesgen, A, W., Chien, WT., \& Bressington, D. (2019). Factors influencing subjective recovery of people with recent-onset psychosis: A cross-sectional study in a low-income Sub-Saharan country. Psychiatry Research, 274, 421-429. Doi: 10.1016/j.psychres.2019.01.107

Trompenaars, F.J., Masthoff, E.D., Van Heck, G. L., Hodiamont, P. P. \& De Vries, J. (2006). Relationship between mood related disorders and quality of life in a population of Dutch adult psychiatric outpatients. Depression and Anxiety, 23(6), 353-363. Doi: 10.1002/da.20180

van de Willige, G., Wiersma, D., Nienhuis, F. J., \& Jenner, J. A. (2005). Changes in quality of life in chronic patients: A comparison between EuroQol (EQ-5D) and WHOQoL. Quality of Life Research, 14(2), 441-451. Doi: 10.1007/s11136-004-0689-y

This article is protected by copyright. All rights reserved 
Vancampfort, D., Firth, J., Correll, C. U., Solmi, M., Siskind, D., De Hert, M. \& Stubbs, B. (2019). The impact of pharmacological and non-pharmacological interventions to improve physical health outcomes in people with schizophrenia: a meta-review of meta-analyses of randomized controlled trials. World Psychiatry, 18(1), 53-66. Doi: 10.1002/wps.20614

Vancampfort, D., Firth, J., Schuch, F. B., Rosenbaum, S., Mugisha, J., Hallgren, M., ... \& Carvalho, A. F. (2017). Sedentary behavior and physical activity levels in people with schizophrenia, bipolar disorder and major depressive disorder: a global systematic review and meta-analysis. World Psychiatry, 16(3), 308-315. Doi: 10.1002/wps.20458

Vigo, D., Thornicroft, G., \& Atun, R. (2016). Estimating the true global burden of mental illness. The Lancet Psychiatry, 3(2), 171-178. Doi: 10.1016/S2215-0366(15)00505-2

Vita, A., Perin, A. P., Cavanna, M., Cobelli, F., Rosa, J., Valsecchi, P., ... \& Sacchetti, E. (2019). Negative symptom severity at discharge from an index hospitalization and subsequent use of psychiatric care resources: A retrospective 1-year follow-up study on 450 patients with schizophrenia spectrum disorders. Schizophrenia Research. Doi: 10.1016/j.schres.2019.11.052.

Walker, E. R., McGee, R. E. \& Druss, B. G. (2015). Mortality in mental disorders and global disease implications: a systematic review and meta-analysis. JAMA Psychiatry, 72(4), 334-341. Doi: 10.1001/jamapsychiatry.2014.2502

World Health Organization. (2013). WHO 2013-2020 Mental Health Action Plan. Geneva: WHO. Available from: https://apps.who.int/iris/bitstream/handle/10665/89966/9789241506021_eng. Accessed: $25 / 08 / 2020$

World Health Organization. (2018). Fact sheet 220: Mental Health. Geneva, WHO. Available from: http://www.euro.who.int/_data/assets/pdf_file/0017/348011/Fact-sheet-SDG-Mental- 
health-UPDATE-02-05-2018.pdf

Xiang, Y. T., Weng, Y. Z., Leung, C. M., Tang, W. K., \& Ungvari, G. S. (2007). Quality of life of Chinese schizophrenia outpatients in Hong Kong: relationship to sociodemographic factors and symptomatology. Australian and New Zealand Journal of Psychiatry, 41(5), 442-449. Doi: $10.1080 / 00048670701261228$

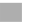

Xiang, Y. T., Shum, D., Chiu, H. F., Tang, W. K., \& Ungvari, G. S. (2010). Association of demographic characteristics, symptomatology, retrospective and prospective memory, executive functioning and intelligence with social functioning in schizophrenia. Australian \& New Zealand Journal of Psychiatry, 44(12), 1112-1117. Doi: 10.3109/00048674.2010.514854

This article is protected by copyright. All rights reserved 


\begin{tabular}{ll}
\hline \multicolumn{2}{l}{ Table 1 Demographic and clinical characteristics of patients (N=347) } \\
\hline Characteristics & $\mathrm{n}(\%)$ \\
\hline Psychiatric diagnosis & \\
Schizophrenia & $217(62.5)$ \\
Psychotic disorder & $23(6.6)$ \\
Depression & $48(13.8)$ \\
Bipolar disorder & $46(13.3)$ \\
Others (e.g. Delusional disorder, hallucinosis) & $13(3.7)$ \\
Gender & \\
Male & $199(57.3)$ \\
Female & $148(42.7)$ \\
Age (Years) & Mean (SD) $41.6(11.8)$ (range 18-64) \\
Employment status & \\
Employed (FT/PT) & $74(21.4)$ \\
Unemployed & $255(73.5)$ \\
Others (housewife, retired, student) & $18(5.2)$ \\
Education level & $187(53.9)$ \\
No formal education &
\end{tabular}

This article is protected by copyright. All rights reserved 
Christian/Catholic

Buddhism

Others (e.g. Ancestor worship, Taoism)

Any other physical illness

No

Yes (e.g. asthma, chronic heart disease, or COPD) r

Duration of receiving psychiatric treatment/service (Months)

The frequency of hospitalization (Days)

Duration of hospitalization (Days)
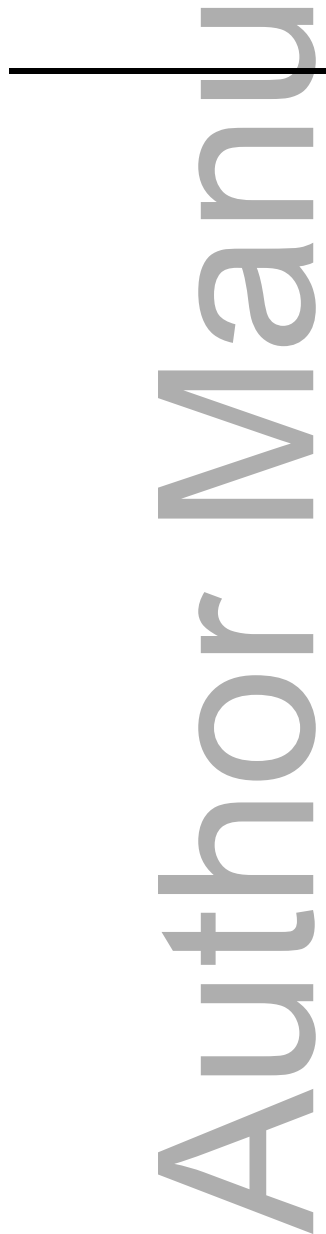

$106(30.6)$

$30(8.6)$

$24(6.9)$

$242(69.7)$

$105(30.3)$

Mean (SD) = 131.1 (130.6) $($ range=1-

507)

Mean $(S D)=3.5(4.4)($ range $=0-32)$

Mean (SD) = 33.6 (28.1) (range=2-

180) 


\begin{tabular}{|c|c|c|}
\hline Instruments \& Score range & $\begin{array}{l}\text { Raw mean } \\
\text { score (SD) }\end{array}$ & Item mean score (SD, range) \\
\hline \multicolumn{3}{|l|}{ WHOQOL-BREF } \\
\hline Social relationship (4-20) & $10.70(3.12)$ & \\
\hline Environment (4-20) & $16.30(4.21)$ & \\
\hline Physical health (4-20) & $15.52(2.65)$ & \\
\hline Psychological health (4-20) & $14.10(2.24)$ & \\
\hline Overall QoL (1-5) & $4.21(0.91)$ & \\
\hline Overall health (1-5) & $4.15(1.06)$ & \\
\hline $\begin{array}{l}\text { Positive and Negative Syndrome Scale } \\
\text { (PANSS) -total score (30-210) }\end{array}$ & $112.46(23.41)$ & \\
\hline Positive symptoms (7-49) & $19.66(9.83)$ & $2.89(1.90,1-6)$ \\
\hline Negative symptoms (7-49) & $20.85(8.86)$ & $2.91(1.98,1-6)$ \\
\hline $\begin{array}{l}\text { General psychopathology symptoms } \\
(16-102)\end{array}$ & $67.82(28.11)$ & $4.30(2.48,1-7)$ \\
\hline $\begin{array}{l}\text { Specific Level of Functioning (SLOF)-total } \\
\text { score (43-215) }\end{array}$ & $173.24(15.02)$ & \\
\hline Self-maintenance (12-60) & $53.34(5.20)$ & $4.44(0.41,2-5)$ \\
\hline Physical functioning (5-25) & $21.65(3.26)$ & \\
\hline Personal care skills (7-35) & $31.69(3.52)$ & \\
\hline Social functioning (14-70) & $57.34(8.01)$ & $4.09(0.30,2-5)$ \\
\hline Interpersonal relationships (7-35) & $30.03(4.72)$ & \\
\hline Social acceptability (7-35) & 30.31 (4.59) & \\
\hline Community living skills (17-85) & $64.76(10.11)$ & $3.81(0.62,1-5)$ \\
\hline Activities (11-55) & $46.19(5.24)$ & \\
\hline Work skills (6-30) & $22.57(6.88)$ & \\
\hline
\end{tabular}


Table 3 Correlations between patient's QoL/symptoms and functioning (SLOF score)

\begin{tabular}{ll}
\hline Pearson Correlation Coefficients & SLOF-total \\
\hline WHOQOL-Bref & $0.211^{* *}$ \\
Physical health & $0.192^{* *}$ \\
Psychological & $0.188^{* *}$ \\
Social relationships & $0.145^{* *}$ \\
Environment & $0.062^{*}$ \\
Overall QoL & 0.060 \\
Overall health & \\
& $-0.426^{* *}$ \\
PANSS-total & $-0.227^{* *}$ \\
Positive symptoms & $-0.467^{* *}$ \\
Negative symptoms & $-0.368^{* *}$ \\
General psychopathology symptoms
\end{tabular}

$* \mathrm{P}<0.05 ; * * \mathrm{P}<0.01 ; * * * \mathrm{P}<0.001$. 


\begin{tabular}{|c|c|c|c|c|c|}
\hline Variables & B & Std. Error & Beta* & $t$ & $p$ \\
\hline \multicolumn{6}{|l|}{5} \\
\hline Gender & -.366 & 1.589 & -.012 & -.230 & .818 \\
\hline & .018 & .081 & .014 & .220 & .826 \\
\hline Employment status (Employed Vs Others) & 4.763 & 1.883 & .128 & 2.529 & .012 \\
\hline Education level (secondary school or above Vs & 5.828 & 2.038 & .153 & 2.859 & .005 \\
\hline lower) & & & & & \\
\hline $\begin{array}{l}\text { Residential status (living alone Vs living with } \\
\text { others) }\end{array}$ & -4.495 & 1.943 & -.116 & -2.313 & .021 \\
\hline No. of types of medication used & -.919 & .796 & -.060 & -1.155 & .249 \\
\hline No. of types of side-effects reported & 1.263 & .917 & .071 & 1.377 & .170 \\
\hline $\begin{array}{l}\text { Religion (Christian/Catholic/Buddhism Vs } \\
\text { None/unclear) }\end{array}$ & 1.077 & 1.535 & .036 & .702 & .483 \\
\hline Any other physical illness (Yes Vs no) & -3.515 & 1.730 & -.107 & -2.032 & .043 \\
\hline $\begin{array}{l}\text { Duration of receiving psychiatric } \\
\text { treatment/services }\end{array}$ & -.024 & .008 & -.205 & -3.055 & .002 \\
\hline Frequency of hospitalization & .271 & .245 & .066 & 1.106 & .270 \\
\hline Duration of hospitalization & -.011 & .029 & -.019 & -.382 & .703 \\
\hline WHOQOL-BREF - Physical & .157 & .481 & .022 & .326 & .744 \\
\hline WHOQOL-BREF - Psychological & .128 & .495 & .020 & .258 & .796 \\
\hline WHOQOL-BREF - Social relationship & .715 & .345 & .122 & 2.072 & .039 \\
\hline WHOQOL-BREF-Environment & -.178 & .479 & -.025 & -.372 & .710 \\
\hline PANSS-total & -.482 & .070 & -.363 & -6.899 & .000 \\
\hline
\end{tabular}

Notes.

$R^{2}=0.596 ;$ Adjusted $R^{2}=0.355, S E=12.446, F(17)=8.904, P<0.001$ (model statistics) 
Beta*: Standardized coefficients of Beta

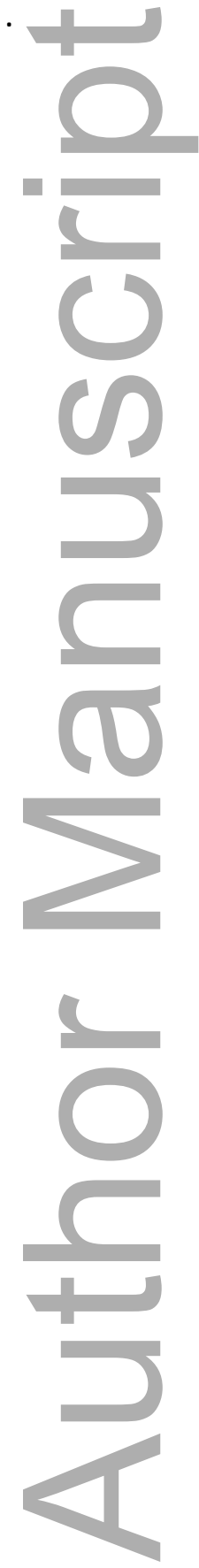

This article is protected by copyright. All rights reserved 


\section{University Library}

\section{- M M N E R VA A gateway to Melbourne's research publications}

Minerva Access is the Institutional Repository of The University of Melbourne

Author/s:

Tong Chien, W;Thompson, DR;Fong Leung, S;Bressington, D

Title:

Quality of life, symptom severity and level of functioning in people with severe mental illness ready for hospital discharge

Date:

2020-11-22

Citation:

Tong Chien, W., Thompson, D. R., Fong Leung, S. \& Bressington, D. (2020). Quality of life, symptom severity and level of functioning in people with severe mental illness ready for hospital discharge. JOURNAL OF PSYCHIATRIC AND MENTAL HEALTH NURSING, 29 (1), pp.14-24. https://doi.org/10.1111/jpm.12703.

Persistent Link:

http://hdl.handle.net/11343/276634 